\title{
Decadal Shift of NAO-Linked Interannual Sea Level Variability along the U.S. Northeast $\operatorname{Coast}^{\mathscr{D}}$
}

\author{
JESSICA S. KENIGSON AND WEIQING HAN \\ Department of Atmospheric and Oceanic Sciences, University of Colorado Boulder, Boulder, Colorado \\ BALAJI RAJAGOPALAN \\ Department of Civil, Environmental, and Architectural Engineering, University of Colorado Boulder, \\ Boulder, Colorado \\ YANTO \\ Department of Civil Engineering, Jenderal Soedirman University, Purwokerto, Indonesia \\ MIKE JASINSKI \\ Hydrological Sciences Laboratory, NASA Goddard Space Flight Center, Greenbelt, Maryland
}

(Manuscript received 14 June 2017, in final form 9 March 2018)

\begin{abstract}
Recent studies have linked interannual sea level variability and extreme events along the U.S. northeast coast (NEC) to the North Atlantic Oscillation (NAO), a natural internal climate mode that prevails in the North Atlantic Ocean. The correlation between the NAO index and coastal sea level north of Cape Hatteras was weak from the 1960s to the mid-1980s, but it has markedly increased since around 1987. The causes for the decadal shift remain unknown. Yet understanding the abrupt change is vital for decadal sea level prediction and is essential for risk management. Here we use a robust method, the Bayesian dynamic linear model (DLM), to explore the nonstationary NAO impact on NEC sea level. The results show that a spatial pattern change of NAO-related winds near the NEC is a major cause of the NAO-sea level relationship shift. A new index using regional sea level pressure is developed that is a significantly better predictor of NEC sea level than is the NAO and is strongly linked to the intensity of westerly winds near the NEC. These results point to the vital importance of monitoring regional changes of wind and sea level pressure patterns, rather than the NAO index alone, to achieve more accurate predictions of sea level change along the NEC.
\end{abstract}

\section{Introduction}

Sea level variability on various time scales affects coastal populations. Climate models suggest that on decadal to multidecadal time scales, anthropogenic warming and Greenland Ice Sheet melt stabilize the stratification of the water column near deep-water formation sites in the North Atlantic, weakening the

\footnotetext{
Supplemental information related to this paper is available at the Journals Online website: https://doi.org/10.1175/JCLI-D-170403.s1.
}

Corresponding author: Jessica S. Kenigson, jessica.kenigson@ colorado.edu
Atlantic meridional overturning circulation (AMOC) and causing dynamic sea level rise along the U.S. northeast coast (NEC) (Yin et al. 2009; Hu et al. 2011). Experiments with eddy-permitting $\left(0.25^{\circ}\right)$ ocean models suggest that because of geostrophy, there is an inverse relationship between sea level along the northeast coast of North America and AMOC transport at a rate of approximately $-2 \mathrm{~cm} \mathrm{~Sv}^{-1}\left(1 \mathrm{~Sv} \equiv 10^{6} \mathrm{~m}^{3} \mathrm{~s}^{-1}\right)$ on interannual time scales (Bingham et al. 2007; Bingham and Hughes 2009). However, other experiments suggest that north of Cape Hatteras, local wind stress rather than the AMOC is the dominant driver of interannual sea level variability (Andres et al. 2013; Woodworth et al. 2014; Piecuch et al. 2016). Local winds are influenced by the North Atlantic Oscillation (NAO), which 
is the dominant pattern of basin-scale interannual sea level pressure variability over the North Atlantic Ocean and is most prominent during the winter months (Hurrell 1995). During positive NAO phases, the pressure gradient between the subtropical Azores high and the subpolar Icelandic low intensifies, driving intensified westerly winds across the basin. Goddard et al. (2015) have suggested that both reduced AMOC transport and NAO-linked nearshore wind anomalies accompanied the 1-in-850-yr extreme sea level rise event of 2009/10; Piecuch and Ponte (2015), however, have found that the inverse barometer effect explains about $50 \%$ of the sea level variation in this event.

If local wind stress is indeed a primary driver of interannual NEC sea level variability, then it is puzzling that the wintertime NAO impact on wintertime coastal sea level along the northwest Atlantic shelf has been found to be weak over some of the periods studied (1977-2001, 1935-77, and 1899-1935) (Woolf et al. 2003). However, the difference in annual mean sea level from the tide gauges at Key West, Florida, and New York City, New York (7-yr low-pass filtered) has been found to be correlated with the annual mean NAO index for much of the twentieth century, since the correlation coefficient exceeds that between the NAO index and the tide gauge record at each station alone; sea level variability common to both records that is not associated with the NAO is removed in the differencing (Woodworth et al. 2017). Since 1987 a different situation has been found; the correlation between the wintertime NAO index and sea level anomalies (SLAs) north of Cape Hatteras has become strongly negative, likely as a result of forcing by NAO-associated local along-shelf wind stress and potentially remote wind stress curl over the Labrador Sea (Andres et al. 2013). The aim of this paper is to investigate the variations, both spatially (along the coast) and temporally (regime shifts), in the relationship between the NAO and U.S. East Coast sea level and identify the physical causes of the varying relationship. In section 2 we discuss the data and methods of our study, including a key analytical tool, Bayesian dynamic linear regression modeling. In section 3 we analyze the relationship between the NAO and sea level anomalies and present a proposed mechanism. Finally, in section 4 we summarize the principal findings.

\section{Data and methods}

Four regional groups of SLAs are constructed by averaging tide gauge records of annual mean revised local reference (RLR) sea level in and around the Gulf of Maine (GoM), the Mid-Atlantic Bight (MAB), the Chesapeake Bay (CB), and the South Atlantic Bight
(SAB; Fig. 1 and Table S1 in the supplemental material) (Holgate et al. 2013; PSMSL 2014). Tide gauge records must span 1950-2013 and be at least 80\% complete, and missing data are infilled via regression of (detrended) anomalies onto selected nearby tide gauge records. Prior to the averaging, a linear time trend is removed from each record. Various infilling methods (including simple linear interpolation) have been tested and the major findings are robust with respect to the choice of method.

To understand the nonstationary impact of the NAO and to explore the causes for the NEC sea level variability, we analyze tide gauge observations of sea level, satelliteobserved winds, and atmospheric reanalysis products. The Hurrell station-based December-March (DJFM) mean NAO index (1865-present) is obtained online (Hurrell and NCAR Research Staff 2017). The NCEP-NCAR reanalysis (Reanalysis-1, 1948-present; Kalnay et al. 1996) and Twentieth Century Reanalysis, version 2c (1851-2014; Compo et al. 2011), momentum flux/wind stress and sea level pressure data are provided by NOAA/OAR/ESRL Physical Sciences Division, Boulder, Colorado and are obtained online from their website (https://www.esrl.noaa.gov/ psd/data/gridded/data.20thC_ReanV2c.html). In addition, the monthly mean Reanalysis-1 wind stress curl is downloaded from the KNMI Climate Explorer website (https:// climexp.knmi.nl/selectfield_rea.cgi). The Reanalysis-1 monthly mean surface wind stress (spectral T62 Gaussian grid; $192 \times 94$ grid at $\sim 2^{\circ}$ resolution), wind stress curl, and sea level pressure $\left(2.5^{\circ} \times 2.5^{\circ}\right)$ are averaged to form the annual mean. The Twentieth Century Reanalysis 0.995-sigma level, 6-hourly zonal and meridional winds $\left(2.0^{\circ} \times 2.0^{\circ}\right)$ are used to estimate the annual mean zonal and meridional wind stress; the monthly mean sea level pressure $\left(2.0^{\circ} \times 2.0^{\circ}\right)$ is averaged to form the annual mean. The Japanese 55-year Reanalysis (Kobayashi et al. 2015) 6-hourly surface zonal and meridional winds $\left(1.25^{\circ} \times 1.25^{\circ}\right)$, available for 1958 -present, are used to estimate the annual mean zonal and meridional wind stress, and the monthly mean sea level pressure $\left(1.25^{\circ} \times\right.$ $\left.1.25^{\circ}\right)$ is averaged to form the annual mean. The JRA-55 wind and sea level pressure data are available online [6-hourly (Japan Meteorological Agency 2013a) and monthly (Japan Meteorological Agency 2013b)]. The Cross-Calibrated Multi-Platform (CCMP; Atlas et al. 2011) ocean surface wind vector analyses' monthly mean pseudostress $\left(0.25^{\circ} \times 0.25^{\circ}\right)$ is obtained from online (https://podaac-opendap.jpl.nasa.gov/opendap/allData/ $\mathrm{ccmp} / \mathrm{L} 3.5 \mathrm{a} / \mathrm{monthly} / \mathrm{flk} /$ ) and is used to estimate the annual mean wind stress. Finally, the Met Office Hadley Centre monthly mean sea level pressure dataset (HadSLP2 at 5.0 $\times 5.0^{\circ}$; Allan and Ansell 2006) is obtained from online (https://www.metoffice.gov.uk/hadobs/ hadslp2/) and is averaged to form the annual mean. 

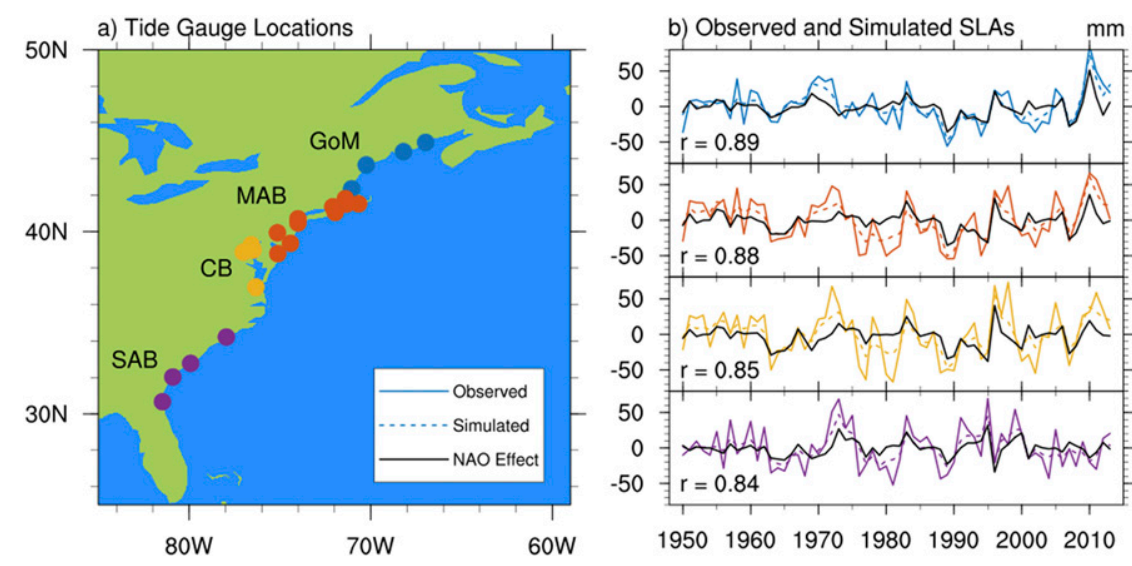

FIG. 1. (a) Tide gauges used to construct the time series of SLAs in and around the GoM, MAB, CB, and SAB. (b) Observed SLAs in the GoM, MAB, CB, and SAB (solid colored lines) and Bayesian DLM $\left(\beta_{0, t}+\beta_{1, t} \mathrm{NAO}_{t}\right)$ of SLAs with DJFM NAO index $\left(X_{1, t}\right)$ as predictor (dashed colored lines). Black lines represent the estimated NAO contribution $\left(\beta_{1, t} \mathrm{NAO}_{t}\right)$ alone. Also indicated are correlations between observed SLAs and DLM-modeled SLAs.

The Bayesian dynamic linear model (DLM) (Petris et al. 2009) is a generalization of the static linear regression model (SLM) in that the DLM permits timevarying model coefficients, compared to the constant coefficients of the SLM. Consequently, the DLM can capture nonstationary relationships between the predictors and predictand, which is more realistic than the "static" relationship described by the SLM, since climate variability (e.g., NAO) often has a nonstationary relationship with sea level (see section 1). Indeed, this method has recently been used to understand the nonstationary influence of internal climate modes on the Indian monsoon, and Indonesian rainfall and IndoPacific Walker circulations (Krishnaswamy et al. 2015; Yanto et al. 2016; Han et al. 2017). Other Bayesian statistical methods have recently been used in a wide variety of contexts (Kwon and Lall 2016; Sarhadi et al. 2016; Piecuch et al. 2017).

Specifically, the Bayesian DLM involves two sets of equations:

$$
\begin{aligned}
& Y_{t}=\beta_{0, t}+\sum_{i} \beta_{i, t} X_{i, t}+\varepsilon_{t} \quad \text { and } \\
& \beta_{i, t}=\beta_{i, t-1}+w_{i, t}, \quad \text { for } i=0, \ldots, p-1,
\end{aligned}
$$

where $Y_{t}$ and $X_{i, t}$ are time series of the predictand and $p-1$ predictor variables, respectively; $\beta_{i, t}$ represents a time-varying coefficient; $\varepsilon_{t}$ is an error term; and $w_{i, t}$ is a noise term. Here, $\beta_{0, t}$ represents a time-varying level that is not explained by the predictors. Using Kalman filtering and smoothing, Eqs. (1) and (2) yield coefficients $\beta_{i, t}$ for each time step $t$. A simple example is the DLM with the NEC SLAs as the predictand and the NAO index as the predictor (Fig. 1). For technical details about the
Bayesian DLM, see section 1 in the supplemental material and Han et al. (2017).

\section{Results}

\section{a. Decadal change of NAO impact on NEC SLAs}

The Bayesian DLM with DJFM NAO index as the predictor is able to reasonably simulate the observed coastal sea level variability (cf. the solid and dashed colored curves in Fig. 1). However, the NAO effect varies considerably in time, and the NAO alone can only explain a significant portion of sea level variability after 1987 (cf. the black and colored curves). The NAO influence on coastal SLAs reveals two distinct decadal regimes north of Cape Hatteras but not to the south (Figs. 1 and 2). From 1960 to 1986, NAO-SLA correlations are negligible or positive in all four regions shown in Fig. 1 (see Table S2 in the supplemental material). In contrast, beginning around 1987 the correlations abruptly reverse sign north of Cape Hatteras (Fig. 2 and Table S2). As the tide gauge at New York City has a nearly continuous record over the $100-\mathrm{yr}$ period since 1893 , it is particularly instructive to compare the NAO-sea level relationship prior to 1950 with that of the later period (Fig. S1b in the supplemental material). During the period 1893-2013, the correlation between the SLAs and the DJFM NAO index is weak $(r=-0.17)$. This weak relationship is consistent with the weak correlation between the SLAs at New York and the annual mean NAO index found by Woodworth et al. (2017), with $r=-0.14$ for 1913-2014 ( $r=-0.37$ for the 7-yr low-pass-filtered data). From the early 1890s to the 1940s, the relationship between the NAO and sea 

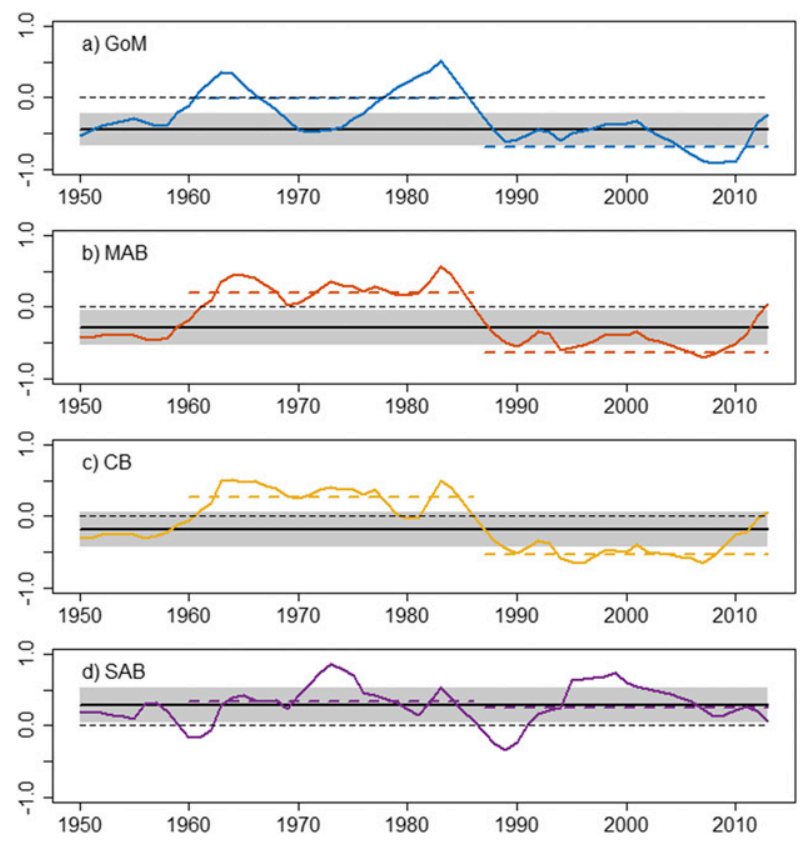

FIG. 2. Results from the Bayesian DLM for each of the four regions shown in Fig. 1. Colored curves show coefficients $\beta_{1, t}$ from the Bayesian DLM of SLAs in each region [ $Y_{t}$ in Eqs. (1) and (2)] with DJFM NAO index as predictor $X_{1, t}$ over 1950-2013. Also shown are the corresponding SLM regression coefficients $b_{1}$ (i.e., percent of the observed standard deviation in SLAs explained by NAO) from 1950 to 2013 (solid black lines) and 95\% confidence intervals on the SLM coefficient (gray-shaded region), SLM coefficients during 1960-86 and 1987-2013 (dashed colored lines), and zero lines (dashed black lines). Since the NAO index and SLAs are normalized by their standard deviations, the SLM coefficients are equal to correlation coefficients.

level at New York was overall weakly positive, with considerable nonstationarity. However, the strongly negative relationship during 1987-2013 has a precedent, in that a similar event occurred during the 1950s. This suggests that the relationship shift during 1987-2013 may not be a "permanent" shift related to the long-term trend but a component of natural variability. In fact, nonstationary relationships between the NAO and the North Atlantic sea surface temperature, surface air temperature, and sea level pressure exist on time scales ranging from interannual to decadal (Polyakova et al. 2006; Xu et al. 2016).

\section{b. Decadal change of NAO-linked winds and sea level pressure}

Northeastward (southwestward) along-shelf wind drives off-shelf (on shelf) Ekman transport and therefore induces coastal upwelling (downwelling), causing sea level fall (rise) along the coast. The cross-shelf sea level gradient is in balance with an along-shelf geostrophic current that flows in the direction of the wind,
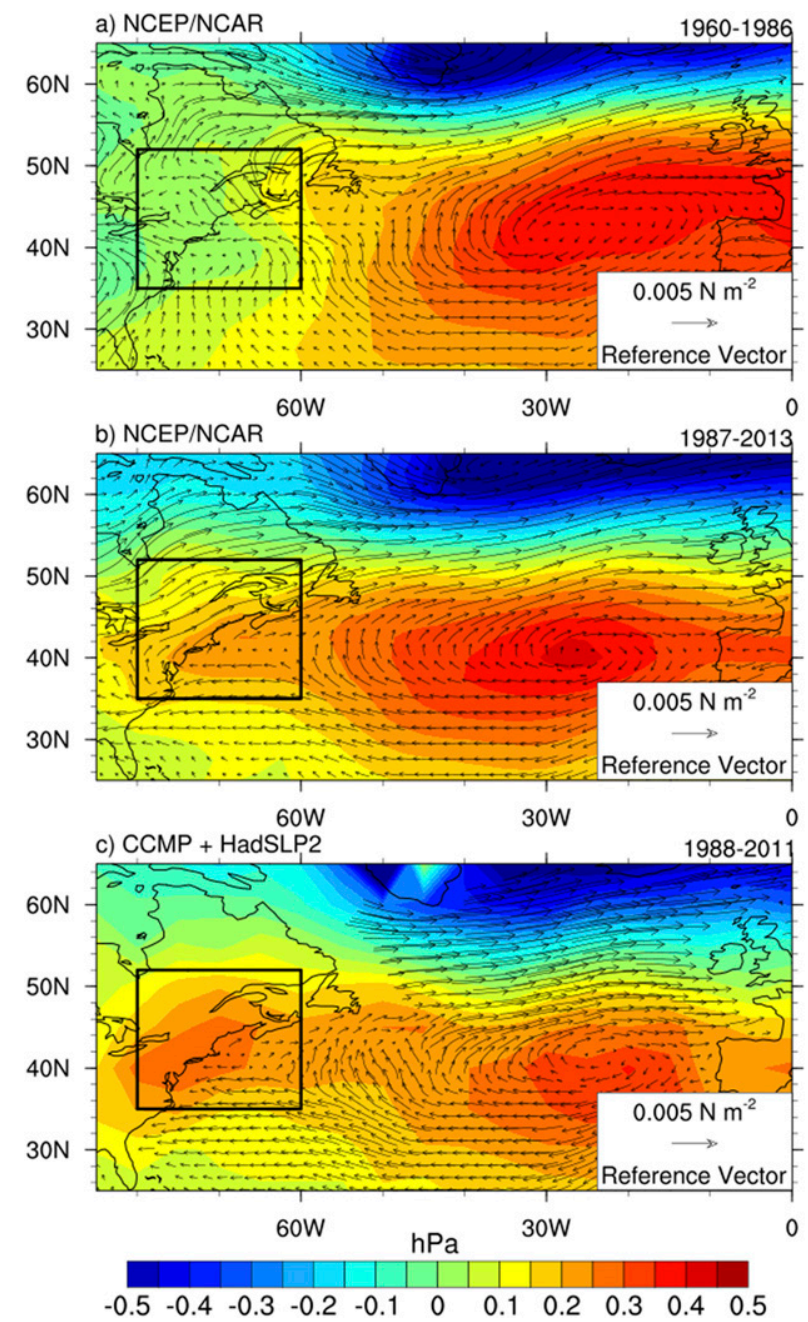

FIG. 3. (a) Regression pattern of annual mean Reanalysis-1 sea level pressure (color shading) and wind stress (arrows) for the period 1960-86 on the DJFM NAO index. (b) As in (a), but for 1987-2013. (c) As in (a), but for HadSLP2 sea level pressure (color shading) and satellite-observed CCMP wind stress (arrows) for 1988-2011. The period 1988-2011 shown is constrained by CCMP, version 1.1, data availability. The local region with a marked shift in NAO-linked winds and sea level pressure is indicated by the rectangle.

with high sea level to its right in the Northern Hemisphere. Consequently, the local along-shelf wind should be negatively correlated with coastal SLAs along the NEC. However, nearshore wind stress is not consistently represented by the NAO index. Between 1960-86 and 1987-2013, the NAO-linked sea level pressure and surface wind patterns in the NEC region experienced striking changes, even though the large-scale patterns over the North Atlantic basin remained similar (Figs. 3 and 4). NAO-linked winds north of Cape Hatteras are comparatively cross shelf and perpendicular to the coast from 1960 to 1986 but parallel to the coast from 1987 to 

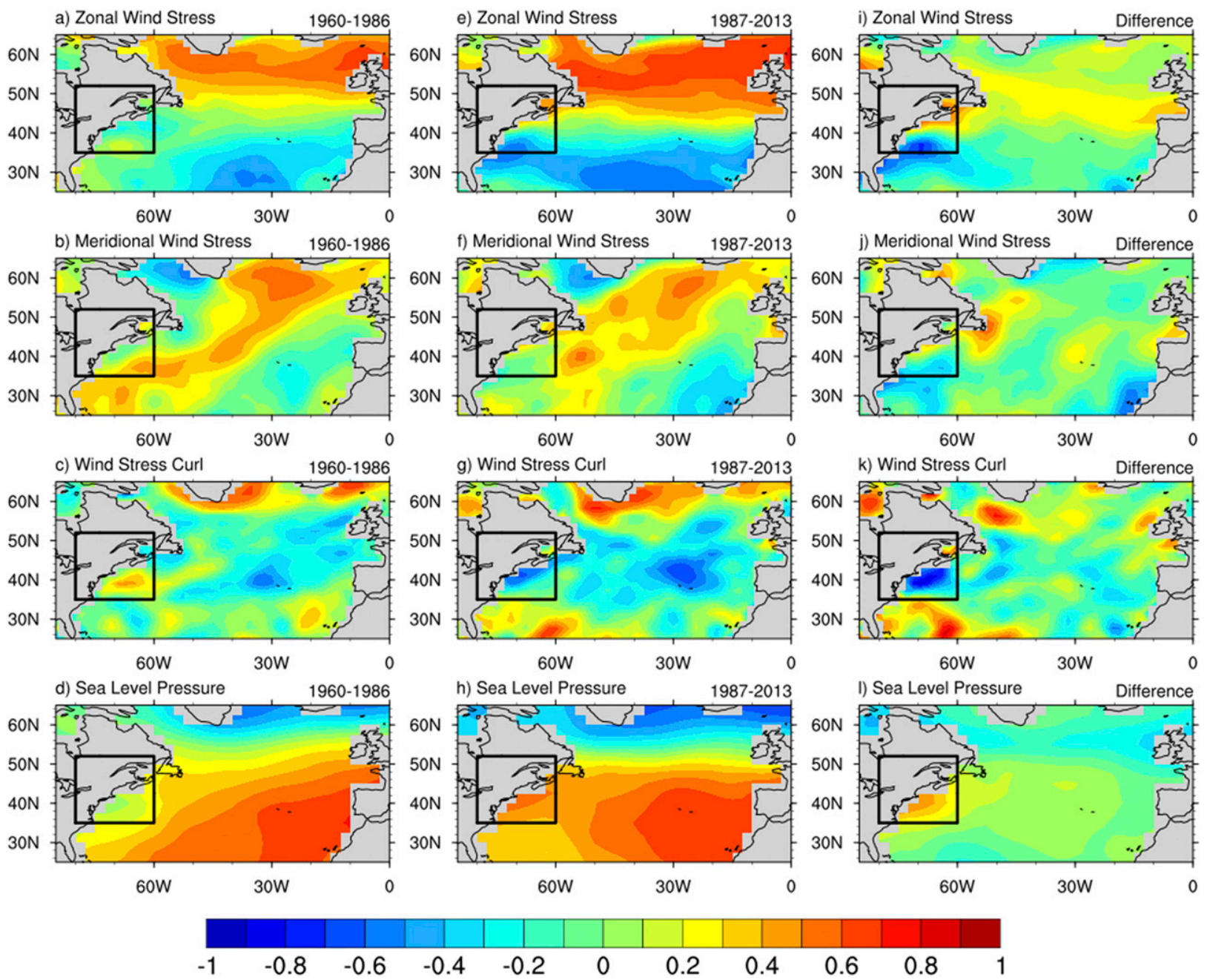

FIG. 4. (a) Correlation coefficients between the DJFM NAO index and the annual mean Reanalysis-1 zonal wind stress for 1960-86. (b) As in (a), but for meridional wind stress. (c) As in (a), but for wind stress curl. (d) As in (a), but for sea level pressure. (e)-(h) As in (a)-(d), respectively, but for 1987-2013. (i)-(1) Difference between correlation coefficients for 1987-2013 and 1960-86. The local region with a marked shift in NAO-linked winds and sea level pressure is indicated by the rectangle.

2013. Surface wind and sea level pressure patterns from Reanalysis-1, JRA-55, and the Twentieth Century Reanalysis together with sea level pressure from HadSLP2 and satellite-observed CCMP winds are all consistent, suggesting that the signals are robust to cross-dataset differences (Figs. 3b,c and Fig. S2 in the supplemental material).

NAO-associated winds and sea level pressure remain similar before and after 1987 over the basin interior generally but not within the NEC, where correlations between the NAO and zonal wind stress, meridional wind stress, wind stress curl, and sea level pressure markedly change or reverse sign (Fig. 4). However, in the remote Labrador Sea region, wind stress curl has been shown to correlate with NEC SLAs from 1970 to 2012 (Andres et al. 2013); correlations between the
NAO and Labrador Sea wind stress curl increased during 1987-2013 relative to 1960-86 (Fig. 4k), suggesting the possibility that this shift in wind stress curl may also have contributed to the decadal shift of the NAO-SLA relationship.

\section{c. Effect of regional wind stress on NEC sea level variability}

The NEC SLAs are significantly correlated with local and remote winds throughout the 1950-2013 period. Specifically, SLAs within the Mid-Atlantic Bight are highly correlated with remote sea level pressure loci within the central United States $\left(35.0^{\circ} \mathrm{N}, 87.5^{\circ} \mathrm{W}\right)$ and the North Atlantic $\left(57.5^{\circ} \mathrm{N}, 55.0^{\circ} \mathrm{W}\right)$ (Fig. 5); the latter location is near a region in the Labrador Sea over which the wind stress curl has been shown to correlate with 
a) SLA-SLP Correlation Pattern

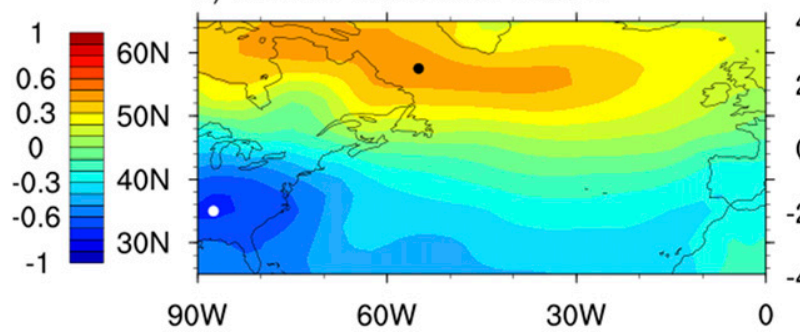

b) WAI

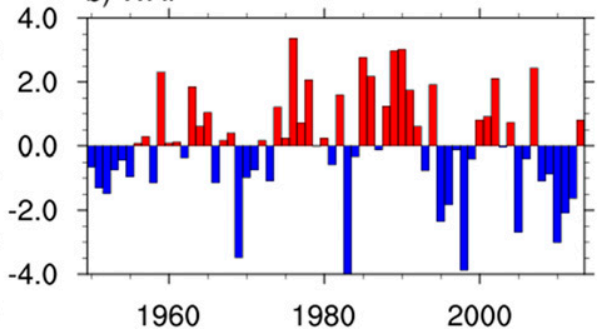

FIG. 5. (a) Correlation coefficients between SLAs in the MAB and Reanalysis-1 sea level pressure from 1950 to 2013. Grid points of maximum correlation and anticorrelation are shown by the black and white dots, respectively $\left(57.5^{\circ} \mathrm{N}, 55.0^{\circ} \mathrm{W}\right.$ and $\left.35.0^{\circ} \mathrm{N}, 87.5^{\circ} \mathrm{W}\right)$. (b) Difference between normalized sea level pressure at the two grid points previously indicated, defined as the WAI discussed in the text.

SLAs along the Atlantic shelf (Andres et al. 2013). For this reason we construct a west Atlantic index (WAI) by normalizing the sea level pressure time series at each locus and then taking the difference (Fig. 5). The WAI is associated with a large-scale atmospheric circulation pattern with a strong along-shelf wind component near the western boundary of the North Atlantic (Fig. 6a), but it is only weakly correlated with the NAO $(r=0.21$ for DJFM NAO index and $r=0.31$ for annual mean NAO index) for 1950-2013. Unlike the NAO the WAI is strongly related to SLAs throughout 1950-2013 in the Gulf of Maine, the Mid-Atlantic Bight, and the Chesapeake Bay but not the South Atlantic Bight (Figs. S3 and S4 and Table S2). Basin-scale spatial patterns of wind stress and sea level pressure associated with the WAI and DJFM NAO index are similar, consisting of a sea level pressure dipole between the subtropical basin interior and the subpolar regions. However, the NAOassociated nearshore wind pattern is relatively cross shelf (Fig. 6b), while the WAI-associated pattern is relatively along shelf (Fig. 6a), providing additional evidence that local and regional along-shelf wind stress is a strong driver of interannual sea level variability. From 1987 to 2013, the NAO influence on sea level pressure extends westward and produces along-shelf wind stress anomalies similar to the WAI pattern (Fig. 3b and Fig. S2), which explains the intensified NAO-SLA correlation north of Cape Hatteras.

The NAO is not strongly correlated with the areamean along-shelf wind stress in and around the MidAtlantic Bight, partly because of the changes in the sign of the correlation with the zonal wind stress (Fig. 4). Therefore, principal component analysis is used to extract leading modes of along-shelf [i.e., $70^{\circ}$ east from north (or $20^{\circ}$ north of east)] wind stress variability over the ocean in the region of $35^{\circ}-52^{\circ} \mathrm{N}, 80^{\circ}-60^{\circ} \mathrm{W}$. The two leading principal components (PCs; Fig. S5 in the supplemental material) of regional along-shelf wind stress explain approximately $75 \%$ of the total variance from 1948 to 2013 (Fig. S6). While the NAO index is independent of the leading PC (PC1) throughout 1950-2013, it is significantly correlated with PC2 after 1987 (Table S2 and Figs. S7 and S8). This strengthens the case that the NAO is associated with significant variability in regional winds from 1987 to 2013 but not from 1960 to 1986.

The relationship between the regional along-shelf wind stress and SLAs north of Cape Hatteras can help to illuminate the causes of the decadal reversal of the relationship between the NAO and SLAs. PC1 has a strongly negative relationship with SLAs in the South Atlantic Bight, the Chesapeake Bay, and the MidAtlantic Bight from 1960 to 1986 that weakens considerably from 1987 to 2013. In the South Atlantic Bight, PC1 is relatively influential over both periods. These relationships are also clearly captured by the Bayesian DLM (Figs. S9-S16 in the supplemental material). Therefore, regional winds independent of NAO are a significant driver of sea level variability from 1960 to 1986. The leading empirical orthogonal function (EOF1) of wind stress anomalies corresponding to PC1 is unipolar over the region of interest (Fig. S5), and the negative correlation north of Cape Hatteras is consistent with a hypothesized Ekman transport mechanism (Andres et al. 2013).

In contrast, the relationship between PC2 and SLAs north of Cape Hatteras is weak from 1960 to 1986, but it strengthens considerably from 1987 to 2013 when PC2 becomes significantly correlated with the NAO (Table S2). PC2 corresponds to a spatial dipole mode of along-shelf winds (EOF2), with positive anomalies near the Gulf of Maine and negative anomalies around the Chesapeake Bay and the southern Mid-Atlantic Bight (Fig. S5). The negative correlation between PC2 and SLAs in the Gulf of Maine is consistent with an Ekman transport mechanism, but the negative correlation in the southern MidAtlantic Bight and the Chesapeake Bay is not, since 

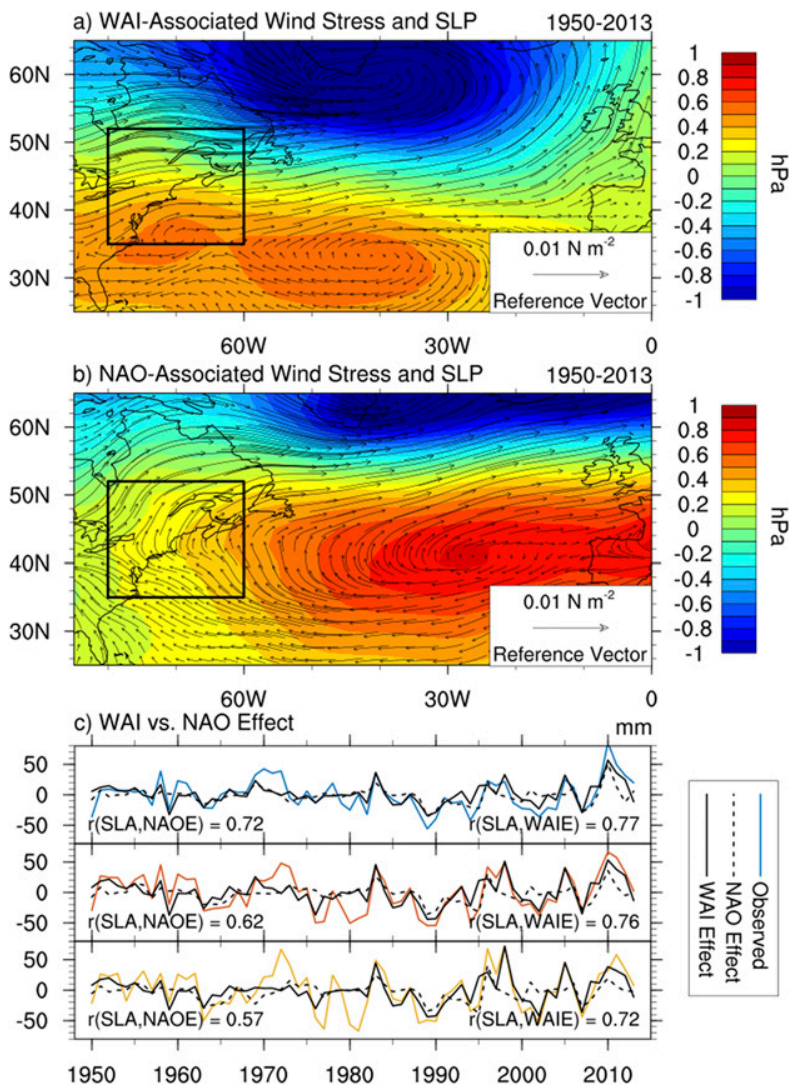

FIG. 6. (a) Regression pattern of Reanalysis-1 sea level pressure (color shading) and surface wind stress (arrows) on the WAI from 1950 to 2013. (b) As in (a), but for DJFM NAO index as predictor. Each regression model is fit separately. To facilitate a comparison, predictors are renormalized to have zero mean and unit variance from 1950 to 2013. Results for annual mean NAO are similar in spatial pattern with increased intensity in some regions. (c) Solid colored lines show observed SLAs in the GoM, MAB, and CB (see Fig. 1a for region colors); dashed black lines show NAO contribution $\left[\beta_{1, t} X_{1, t}\right.$ in Eqs. (1) and (2)] in the Bayesian DLM of SLAs; and solid black lines are with WAI as a predictor. Also indicated are correlations between observed SLAs and the DLM-modeled NAO contribution (NAOE) and the WAI contribution (WAIE).

EOF2 in these regions has an opposite sign compared to the regions in the north. What, then, might explain the sign of the correlation? It has been suggested that annual mean sea level anomalies from tide gauges ranging from the Gulf of Maine to Cape Hatteras are coherent and are highly correlated with a regional average $(r=$ $\sim 0.8-0.9$ ) from 1970 to 2012 (Andres et al. 2013). We propose that the equatorward shelf current on the coastal margin of the Gulf Stream balances a sea level gradient through geostrophy, with a southward current associated with higher coastal sea level along the shelf (Andres et al. 2013; Li et al. 2014). Coastal Kelvin waves driven by the remote along-shelf winds over the Gulf of Maine and the Scotian Shelf propagate southward, opposing the current driven by the local along-shelf wind over the shelf of the Chesapeake Bay and the Mid-Atlantic Bight (Li et al. 2014) and explaining the negative PC2-SLA correlation.

It has been suggested that NAO-linked nearshore wind anomalies cannot fully account for the extreme sea level rise event of 2009/10, since concomitant sea level changes were not observed during strong negative wintertime NAO events (e.g., 1969) (Goddard et al. 2015). Our results suggest that this comparison may be misleading, since we have shown that the NAO had a much weaker relationship with western boundary nearshore winds in the 1960s than during recent decades. Furthermore, NAO-linked regional wind stress anomalies have been a significant driver of interannual sea level variability along the western boundary during recent decades, and findings to the contrary may be explained by treating the NAO-sea level relationship as a stationary one.

\section{Conclusions}

The strength of the correlation between the DJFM NAO index and coastal SLAs north of Cape Hatteras markedly increased over the period of 1987-2013 relative to 1960-86. However, the correlation between the DJFM NAO index and coastal SLAs south of Cape Hatteras remained weak during both periods. The Bayesian DLM is able to capture the time-varying influence of the NAO on SLAs. Using this method we have shown that the decadal shift in the relationship between the NAO and SLAs is related to a spatial pattern shift in the regional winds (particularly the alongshelf component) linked to the NAO. Therefore, we have developed a new sea level pressure index for the west Atlantic region (i.e., the WAI) that is more strongly correlated with coastal SLAs north of Cape Hatteras than the NAO index and is linked to the intensity of westerly winds near the U.S. northeast coast. These results are consistent with numerous recent studies that have identified the dominant role of regional wind stress in driving interannual sea level variability along the northwest Atlantic shelf (Andres et al. 2013; Woodworth et al. 2014; Piecuch et al. 2016). Our results suggest that monitoring fluctuations in regional winds and sea level pressure, rather than the NAO index alone, may be necessary for formulating accurate predictions of interannual sea level changes along the U.S. northeast coast.

Acknowledgments. J. S. Kenigson is supported by NASA Harriett G. Jenkins Graduate Fellowship Program Grant NNX13AR74H. W. Han is supported by 
National Science Foundation (NSF) AGS-1446480, NASA OVWST NNX14AM68G, and NASA OSTST NNX17AI63G. Support for the Twentieth Century Reanalysis Project dataset is provided by the U.S. Department of Energy (DOE), Office of Science, Innovative and Novel Computational Impact on Theory and Experiment (INCITE) program and the Office of Biological and Environmental Research (BER), and by the National Oceanic and Atmospheric Administration Climate Program Office. The Japanese 55-year Reanalysis (JRA-55) dataset used for this study is from the JRA-55 project carried out by the Japan Meteorological Agency (JMA).

\section{REFERENCES}

Allan, R., and T. Ansell, 2006: A new globally complete monthly historical gridded mean sea level pressure dataset (HadSLP2): 1850-2004. J. Climate, 19, 5816-5842, https://doi.org/10.1175/ JCLI3937.1.

Andres, M., G. G. Gawarkiewicz, and J. M. Toole, 2013: Interannual sea level variability in the western North Atlantic: Regional forcing and remote response. Geophys. Res. Lett., $\mathbf{4 0}$, 915-5919, https://doi.org/10.1002/2013GL058013.

Atlas, R., R. N. Hoffman, J. Ardizzone, S. M. Leidner, J. C. Jusem, D. K. Smith, and D. Gombos, 2011: A cross-calibrated, multiplatform mean surface wind velocity product for meteorological and oceanographic applications. Bull. Amer. Meteor. Soc., 92, 157-174, https://doi.org/10.1175/2010BAMS2946.1.

Bingham, R. J., and C. W. Hughes, 2009: Signature of the Atlantic meridional overturning circulation in sea level along the east coast of North America. Geophys. Res. Lett., 36, L02603, https://doi.org/10.1029/2008GL036215.

,,-- V. Roussenov, and R. G. Williams, 2007: Meridional coherence of the North Atlantic meridional overturning circulation. Geophys. Res. Lett., 34, L23606, https://doi.org/10.1029/ 2007 GL031731.

Compo, G. P., and Coauthors, 2011: The Twentieth Century Reanalysis Project. Quart. J. Roy. Meteor. Soc., 137, 1-28, https://doi.org/10.1002/qj.776.

Goddard, P. B., J. Yin, S. M. Griffies, and S. Zhang, 2015: An extreme event of sea-level rise along the Northeast coast of North America in 2009-2010. Nat. Commun., 6, 6346, https://doi.org/10.1038/ncomms7346.

Han, W., G. A. Meehl, A. Hu, J. Zheng, J. Kenigson, J. Vialard, B. Rajagopalan, and Yanto, 2017: Decadal variability of the Indian and Pacific Walker cells since the 1960s: Do they covary on decadal timescale? J. Climate, 30, 8447-8468, https:// doi.org/10.1175/JCLI-D-16-0783.1.

Holgate, S. J., and Coauthors, 2013: New data systems and products at the Permanent Service for Mean Sea Level. J. Coastal Res., 29, 493-504, https://doi.org/10.2112/JCOASTRES-D-12-00175.1.

$\mathrm{Hu}$, A., G. A. Meehl, W. Han, and J. Yin, 2011: Effect of the potential melting of the Greenland Ice Sheet on the Meridional Overturning Circulation and global climate in the future. Deep-Sea Res. II, 58, 1914-1926, https://doi.org/10.1016/ j.dsr2.2010.10.069.

Hurrell, J. W., 1995: Decadal trends in the North Atlantic Oscillation: Regional temperatures and precipitation. Science, $\mathbf{2 6 9}$, 676-679, https://doi.org/10.1126/science.269.5224.676.
—, and NCAR Research Staff, Eds., 2017: The climate data guide: Hurrell North Atlantic Oscillation (NAO) index (stationbased), accessed 2 December 2016, https://climatedataguide. ucar.edu/climate-data/hurrell-north-atlantic-oscillation-naoindex-station-based.

Japan Meteorological Agency, 2013a: JRA-55: Japanese 55-year reanalysis, daily 3-hourly and 6-hourly data, updated monthly. Research Data Archive at the National Center for Atmospheric Research, Computational and Information Systems Laboratory, accessed 3 November 2016, https://doi.org/ 10.5065/D6HH6H41.

_ 2013 b: JRA-55: Japanese 55-year reanalysis, monthly means and variances. Research Data Archive at the National Center for Atmospheric Research, Computational and Information Systems Laboratory, accessed 29 May 2016, https://doi.org/ 10.5065/D60G3H5B.

Kalnay, E., and Coauthors, 1996: The NCEP/NCAR 40-Year Reanalysis Project. Bull. Amer. Meteor. Soc., 77, 437-471, https:// doi.org/10.1175/1520-0477(1996)077<0437:TNYRP>2.0.CO;2.

Kobayashi, S., and Coauthors, 2015: The JRA-55 Reanalysis: General specifications and basic characteristics. J. Meteor. Soc. Japan, 93, 5-48, https://doi.org/10.2151/ jmsj.2015-001.

Krishnaswamy, J., S. Vaidyanathan, B. Rajagopalan, M. Bonell, M. Sankaran, R. S. Bhalla, and S. Badiger, 2015: Nonstationary and non-linear influence of ENSO and Indian Ocean Dipole on the variability of Indian monsoon rainfall and extreme rain events. Climate Dyn., 45, 175-184, https:// doi.org/10.1007/s00382-014-2288-0.

Kwon, H.-H., and U. Lall, 2016: A copula-based nonstationary frequency analysis for the 2012-2015 drought in California. Water Resour. Res., 52, 5662-5675, https://doi.org/10.1002/ 2016WR018959.

Li, Y., R. Ji, P. S. Fratantoni, C. Chen, J. A. Hare, C. S. Davis, and R. C. Beardsley, 2014: Wind-induced interannual variability of sea level slope, along-shelf flow, and surface salinity on the Northwest Atlantic shelf. J. Geophys. Res. Oceans, 119, 24622479, https://doi.org/10.1002/2013JC009385.

Petris, G., S. Petrone, and P. Campagnoli, 2009: Dynamic linear models. Dynamic Linear Models with $R$, Use R Series, Springer, 31-84, https://doi.org/10.1007/b135794_2.

Piecuch, C. G., and R. M. Ponte, 2015: Inverted barometer contributions to recent sea level changes along the northeast coast of North America. Geophys. Res. Lett., 42, 5918-5925, https:// doi.org/10.1002/2015GL064580.

— S. Dangendorf, R. M. Ponte, and M. Marcos, 2016: Annual sea level changes on the North American northeast coast: Influence of local winds and barotropic motions. J. Climate, 29, 4801-4816, https://doi.org/10.1175/JCLI-D-16-0048.1.

- , P. Huybers, and M. P. Tingley, 2017: Comparison of full and empirical Bayes approaches for inferring sea-level changes from tide-gauge data. J. Geophys. Res. Oceans, 122, 22432258, https://doi.org/10.1002/2016JC012506.

Polyakova, E. I., A. G. Journel, I. V. Polyakov, and U. S. Bhatt, 2006: Changing relationship between the North Atlantic Oscillation and key North Atlantic climate parameters. Geophys. Res. Lett., 33, L03711, https://doi.org/10.1029/ 2005 GL024573.

PSMSL, 2014: Tide gauge data. Permanent Service for Mean Sea Level. Subset used: Annual mean revised local reference (RLR) data from the geographical region shown in Figure 1, accessed 26 May 2014, http://www.psmsl.org/data/ obtaining/. 
Sarhadi, A., M. C. Ausín, and M. P. Wiper, 2016: A new timevarying concept of risk in a changing climate. Sci. Rep., 6 35 755, https://doi.org/10.1038/srep35755.

Woodworth, P. L., M. Á. M. Maqueda, V. M. Roussenov, R. G. Williams, and C. W. Hughes, 2014: Mean sea-level variability along the northeast American Atlantic coast and the roles of the wind and the overturning circulation. J. Geophys. Res. Oceans, 119, 8916-8935, https://doi.org/10.1002/2014JC010520.

W. R. Gehrels, V. M. Roussenov, R. G. Williams, and C. W. Hughes, 2017: Variations in the difference between mean sea level measured either side of Cape Hatteras and their relation to the North Atlantic Oscillation. Climate Dyn., 49, 2451-2469, https://doi.org/10.1007/s00382-016-3464-1.

Woolf, D. K., A. G. P. Shaw, and M. N. Tsimplis, 2003: The influence of the North Atlantic Oscillation on sea-level variability in the North Atlantic region. J. Atmos. Ocean Sci., 9, 145-167, https://doi.org/10.1080/10236730310001633803.

Xu, T., Z. Shi, H. Wang, and Z. An, 2016: Nonstationary impact of the winter North Atlantic Oscillation and the response of mid-latitude Eurasian climate. Theor. Appl. Climatol., 124, 1-14, https://doi.org/10.1007/ s00704-015-1396-z.

Yanto, B. Rajagopalan, and E. Zagona, 2016: Space-time variability of Indonesian rainfall at inter-annual and multi-decadal time scales. Climate Dyn., 47, 2975-2989, https://doi.org/ 10.1007/s00382-016-3008-8.

Yin, J., M. E. Schlesinger, and R. J. Stouffer, 2009: Model projections of rapid sea-level rise on the northeast coast of the United States. Nat. Geosci., 2, 262-266, https://doi.org/ 10.1038/ngeo462. 